\title{
PERBEDAAN STATUS KEBERSIHAN GIGI DAN MULUT SISWA SDN I MUNDUNG DAN SDN II MUNDUNG KEC TOMBATU TIMUR
}

\author{
. Jean Henry Raule ${ }^{1}$,Mustapa Bidjuni ${ }^{2}$. \\ 1,2)Jurusan Keperawatan Gigi Poltekkes Kemenkes Manado Jl.RW Monginsisdi Malalayang II Manado \\ E-mail :jeanh1666@gmail.com
}

\begin{abstract}
ABSTRAK
Kesehatan gigi dan mulut merupakan salah saru masalah kesehatan yang banyak di alami oleh berbagai kalangan masyarakat Indonesia dan sering hanya di abaikan begitu saja. RISKESDAS (2013) prevalensi masalah gigi dan mulut penduduk Indonesia mencapai 25,9\%, RISKESDAS (2018) terjadi peningkatan prevalensi menjadi 57,6\% .Di provinsi Sulawesi Utara prevalensi masalah gigi dan mulut tahun 2013: 31,6\%, tahun 2018 mencapai 55,5\%.Tujuan penelitian ini untuk mengetahui Perbedaan Status Kebersihan gigi dan mulut siswa kelas V SDN 1 dan SDN 2 Mundung Kecamatan Tombatu Timur.

Penelitian ini merupakan penelitian komparatif yang menggunakan pendekekatan secara cross sectional" dengan total sampel secara inklusi yaitu 44 siswa di 2 SD masing masing 22 siswa di SD N I dan 22 siswa di SDN II Mundung untuk mendapatkan data oral hygiene index simplified (OHI-S) dengan alat dan bahan yaitu sonde dan disclosing solution.Pengambilan sampel secara total.Hasil pemeriksaan kemudian di aktegorikan menjadi kategori baik (0-1,2), kategori sedang $(1,3-3,0)$ dan kategori buruk $(3,1$ $6,0)$.

Hasil uji Independent t-test, diperoleh mean responden SDN 1 Mundung 2,218 dan mean responden SDN 2 Mundung 2,054 ( $\mathrm{p}=0,430>\alpha=0,05)$, Kesimpulan, tidak ada perbedaan yang signifikan antara siswa kelas V SDN 1 dan SDN 2 Mundung terhadap status kebersihan gigi dan mulut.

\section{Kata kunci : Status Kebersihan Gigi dan Mulut}

\begin{abstract}
Oral and dental health is one of the many health problems experienced by various circles of Indonesian society and often just ignored. RISKESDAS (2013) the prevalence of dental and mouth problems in the Indonesian population reached $25.9 \%$, RISKESDAS (2018) increased prevalence to 57.6\%. In North Sulawesi province the prevalence of dental and oral problems in 2013: 31.6\%, reaching $201855.5 \%$. The purpose of this study was to determine the differences in the cleanliness status of teeth and mouth of fifth grade students of SDN 1 and SDN 2 Mundung, District of East Tombatu.

This study is a comparative study that uses cross sectional approach "with a total sample inclusion of 44 students in 2 elementary schools, each of 22 students at SD NI and 22 students at SDN II Mundung to obtain a simplified oral hygiene index (OHI-S) data with tools and materials namely sonde and disclosing solution. Total sampling. The results of the examination are then categorized into good categories $(0-1,2)$, medium categories (1,3-3,0) and bad categories $(3,1-6,0)$.

Independent t-test results, obtained mean of respondents SDN 1 Mundung 2,218 and mean respondents SDN 2 Mundung 2,054 $(\mathrm{p}=0,430>\alpha=0,05)$, Conclusion, there was no significant difference between students of class V SDN 1 and SDN 2 Mundung on dental and oral hygiene status.
\end{abstract}

Keywords: Hygiene Status of Teeth and Mouth

Volume 2 No. 1 Mei 2019 


\section{PENDAHULUAN}

Mulut merupakan suatu tempat yang amat ideal bagi perkembangan bakteri, karena temperatur, kelembaban dan makanan yang cukup tersedia disana..kebersihan gigi dan mulut di tentukan oleh sisa makanan (food debris), plak, kalkulus, material alba, dan noda (stain) pada permukaan gigi. usaha menjaga kebersihan gigi dan mulut ini begitu penting karena kegiatan yang dilakukan dirumah tanpa ada pengawasan dari siapapun, sepenuhnya tergantung dari pengetahuan, pemahaman kesadaran serta kemauan dari pihak individu untuk menjaga kesehatan mulutnya. ${ }^{1}$

Kesehatan gigi dan mulut di Indonesia masih perlu mendapat perhatian khusus dari tenaga kesehatan gigi dan mulut. Hal ini disebabkan karena sebagian besar masyarakat di Indonesia mengabaikan kesehatan gigi dan mulut mereka sendiri, termasuk anak usia sekolah dasar. Kelompok anak usia sekolah dasar merupakan kelompok yang rentan terhadap penyakit gigi dan mulut sehingga perlu diperhatikan dan dicegah secara baik dan benar. Sebanyak 25,2\% anak berusia 10-14 tahun yang memiliki masalah gigi dan mulut di Indonesia. Kondisi ini dapat berpengaruh pada derajat kesehatan mereka dalam proses tumbuh kembang bahkan masa depan mereka. ${ }^{2}$ Berdasarkan Riset Kesehatan Dasar RISKESDAS tahun (2007) yang dilaksanakan oleh Badan Penelitian dan Pengembangan Kesehatan Republik Indonesia menunjukan bahwa pada kelompok anak usia 10-14 tahun bermasalah dengan kesehatan gigi dan mulut yaitu 20,6 \% dan yang menerima perawatan yaitu $26,6 \%$. Terjadi peningkatan pada RISKESDAS (2013) menjadi $25,2 \%$ anak usia 10-14 tahun bermasalah dengan kesehatan gigi dan mulut dan yang menerima perawatan yaitu $28,3 \%{ }^{2}$
Terkait dengan masalah kesehatan gigi dan mulut, yang dialami oleh anak usia 10-14 tahun tidak lepas dari memelihara kesehatan gigi dan mulut dengan cara menggosok gigi yang baik dan benar. dimana penduduk indonesia hanya 2,3\% menggosok gigi yang benar, sedangkan penduduk indonesia usia 10-14 tahun menggosok gigi yang benar hanya $1,7 \%$ seperti yang dijelaskan dalam Riskesdas (2013). ${ }^{2}$ menggosok gigi sangat erat hubungannya dengan kebersihan gigi dan mulut, didalam penelitian yang dilakukan oleh Sintawati dan Tjahja (2008) bahwa status kebersihan gigi dan mulut masih ditentukan oleh status pendidikan dalam penelitiannya menemukan kebersihan gigi dan mulut pada responden dibawah pendidikan SMP persentase OHI-S baik $(80,3 \%)$ masih dibawa persentase responden diatas pendidikan SMP yaitu $91,4 \% .^{3}$

Berdasarkan hasil penelitian Wirata (2015), didapat bahwa ada perbedaan yang bermakna pada nilai rata-rata kebersihan gigi dan mulut pada siswa SD UKGS aktif dengan SD UKGS yang tidak aktif diwilayah kerja puskesmas II Denpasar Utara. ${ }^{4}$

Sejak januari sampai dengan Maret 2018 sebanyak 48 siswa di wilayah Puskesmas Molompar yang datang memeriksa gigi dengan jumlah karies sebanyak 176.Hasil survei awal yang dilakukan tanggal 5 mei 2018 pada 5 siswa SD Negeri I Mundung diperoleh rata-rata OHI-S yaitu 3,1 sedangkan pada 5 siswa SD Negeri II Mundung diperoleh rata- rata OHI-S yaitu 2,1 kedua hasil survei tersebut melebihi rata rata OHI-S yang ditetapkn oleh Green Vermillion yaitu 0-1,2 yang merupakan kriteria baik. Hasil wawancara dari 5 siswa SD Negeri I dan SD Negeri II Mundung di dapatkan bahwa 4 orang siswa menyikat gigi hanya pada saat pagi sebelum ke sekolah, dan 6 orang siswa yang menyikat giginya 2 kali yaitu pagi dan malam. Uraian data diatas menunjukan bahwa 
kebersihan gigi dan mulut siswa SD Negeri I dan SD Negeri II Mundung di kategorikan buruk. Tujuan penelitian ini untuk mengetahui perbedaan status kebersihan gigi dan mulut Siswa SD Negeri I Mundung dan SD Negeri II Mundung Kecamatan Tombatu Timur.

\section{METODE PENELITIAN}

Jenis penelitian ini bersifat analitik komparatif dengan pendekatan cross sectional study. dilaksanakan pada bulan Juli minggu ketiga tahun 2018 di SD Negeri I Mundung dan SD Negeri II Mundung Kecamatan Tombatu Timur. Variabel dalam penelitian yaitu kebersihan gigi dan mulut (OHI-S).Populasi dalam penelitian yaitu seluruh siswa kelas V SD Negeri I dan SD Negeri II Mundung Kecamatan Tombatu Timur berjumah 44 orang.dengan teknik pengambilan sampel yaitu total populasi dari kriteria inklusi .untuk mengetahui perbedaan status kebersihan gigi dan mulut menggunakan uji statistik Independent t-test dengan menggunakan perangkat lunak SPSS.

\section{HASIL PENELITIAN}

1. Distribusi Responden Menurut Jenis Kelamin Tabel 1. Distribusi Kelompok Menurut Jenis

\begin{tabular}{ccc} 
& Kelamin & \\
\hline Jenis Kelamin & Jumlah & $\begin{array}{c}\text { Presentase } \\
(\%)\end{array}$ \\
\hline Laki-laki & 22 & 50 \\
Perempuan & 22 & 50 \\
\hline Total & 44 & 100 \\
\hline
\end{tabular}

Tabel 1.berdasarkan ditribusi tabel diatas menunjukkan bahwa jenis kelamin perempuan berjumlah 22 responden (50\%) dan jenis kelamin laki-laki berjumlah 22 responden (50\%).
2. Distribusi Responden Menurut Kelompok Umur

Tabel 2. Distribusi Kelompok Menurut Umur

\begin{tabular}{ccc}
\hline Umur & Jumlah & Presentase (\%) \\
\hline 10 & 8 & 18,18 \\
11 & 34 & 77,27 \\
12 & 2 & 4,54 \\
\hline Total & 44 & 100 \\
\hline
\end{tabular}

Tabel 2. menunjukkan bahwa responden paling banyak berada pada kelompok umur 11 yaitu sebanyak 34 responden $(77,27 \%)$, selanjutnya diikuti kelompok umur 10 yaitu sebanyak 8 responden $(18,18 \%)$, dan kelompok umur 12 paling rendah dari kelompok umur lainnya yaitu sebanyak 2 responden (4,54\%).

3. Distribusi Status Kebersihan Gigi Dan Mulut Siswa Kelas V SDN 1 Mundung Kecamatan Tombatu Timur.

Tabel 3. Distribusi Status Kebersihan Gigi Dan Mulut Siswa Kelas V SDN 1Mundung

\begin{tabular}{ccc}
\hline Kriteria & Jumlah & Presentase \% \\
\hline Baik & 2 & 9,09 \\
Sedang & 18 & 81,81 \\
Buruk & 2 & 9,09 \\
\hline Total & 22 & 100 \\
\hline
\end{tabular}

Dari tabel 3. menunjukkan bahwa status kebersihan gigi dan mulut responden paling banyak pada kriteria sedang sebanyak yaitu 18 responden $(81,81 \%)$ dan di ikuti kriteria buruk sebanyak yaitu 2 responden (9,09\%), sedangkan kriteria baik yaitu 2 responden $(9,09 \%)$.

4. Distribusi Status Kebersihan Gigi Dan Mulut Siswa Kelas V SDN 2 Mundung Kecamatan Tombatu Timur. 
Tabel 4. Distribusi Status Kebersihan Gigi Dan Mulut Siswa Kelas V dan SDN 2 Mundung

\begin{tabular}{ccc}
\hline Kriteria & Jumlah & Presentase \% \\
\hline Baik & 0 & 0 \\
Sedang & 21 & 95,45 \\
Buruk & 1 & 4,54 \\
\hline Total & 22 & 100 \\
\hline
\end{tabular}

Dari tabel 4. menunjukkan bahwa status kebersihan gigi dan mulut responden paling banyak pada kriteria sedang sebanyak yaitu 21 responden(86,36\%) dan di ikuti kriteria buruk sebanyak yaitu 1 responden (4,54\%),dan yang paling sedikit pada kriteria baik yaitu 0 responden $(0 \%)$.

5. Hasil Uji Statistik Perbedaan status kebersihan gigi dan mulut siswa kelas V SDN 1 Mundung dan SDN 2 Mundung Kecamatan Tombatu Timur dapat dilihat pada tabel 5 dibawah ini.

Tabel 5. Analisa data perbedaan status kebersihan gigi dan mulut

\begin{tabular}{cccccc}
\hline OHI-S & Mean & SD & SE & $\begin{array}{c}\text { P } \\
\text { value }\end{array}$ & N \\
\hline SDN 1 & 2,218 & 0,793 & 0,169 & & 22 \\
Mundung & & & & 0,430 & \\
SDN 2 & 2,054 & 0,554 & 0,118 & & 22 \\
Mundung & & & & & \\
\hline
\end{tabular}

Rata-rata nilai mean status kebersihan gigi dan mulut SDN 1 Mundung yaitu 2,218 dengan standar deviasi 0,793, sedangkan untuk status kebersihan gigi dan mulut SDN 2 Mundung yaitu 2,054 dengan standar deviasi 0,554. Hasil uji statistikmenunjukan bahwa nilai $p$ pada levene's test yaitu sig. $119>\alpha$ 0,05 maka kedua kelompok tidak ada perbedaan varian, sedangkan nilai $p$ (sig. tailed equal variances assumed $=0,430>\alpha 0,05$ yang artinya tidak ada perbedaan OHI-S pada SDN 1 dan SDN 2 Munndung Kecamatan Tombatu Timur.

\section{PEMBAHASAN}

Mulut merupakan bagian tubuh yang sangat penting, maka harus dijaga kebersihannya. kebersihan gigi dan mulut adalah bebasnya gigi dan mulut dari sisa makanan ,kuman-kuman atau deposit deposit yang merusak gigi. Deposit atau lapisan yang menumpuk pada permukaan gigi dapat di kelompokan menjadi acquired pellicle, materia alba, debris, makanan, plak gigi, dental stain dan kalkulus. ${ }^{5}$

Pada masa anak-anak perilaku menjaga kebersihan mulut sering terabaikan, oleh sebab itu perilaku ini perlu ditanamkan sedini mungkin pada setiap anak karena kesehatan gigi dan mulut merupakan bagian yang memegang peranan penting dalam meningkatkan kualitas dan produktivitas sumber daya manusia.Salah satu cara untuk menjaga kesehatan gigi yaitu dengan menyikat gigi, dengan demikian maka kebersihan gigi dan mulut pun terjaga.

Hasil penelitian status kebersihan gigi dan mulut siswa kelas V SDN 1 dan SDN 2 Mundung Kecamatan Tombatu Timur menunjukan bahwa 18 responden $(81,81 \%)$ SDN 1 Mundung memiliki kriteria kebersihan gigi dan mulut yang sedang,kriteria baik $2 \quad(9,09 \%)$ responden sedangkan untuk kriteria buruk dan kriteria baik masing masing $2(9,09 \%)$ responden, sedangkan OHIS untuk SDN 2 Mundung, sebanyak 21 $(95,45 \%)$ responden memiliki kriteria kebersihan gigi dan mulut yang sedang, diikuti kriteria buruk 1 
responden $(4,54 \%)$ dan untuk kriteria baik sebanyak 0 responden $(0 \%)$.

Informasi data ini menunjukan bahwa kedua kelompok responden siswa SDN 1 Mundung dan SDN 2 Mundung memiliki nilai OHI-S dengan kriteria sedang. terjadi kesamaan dalam kriteria tersebut dikarenakan responden baik di SDN 1 mundung maupun SDN 2 mundung memiliki kebiasaan yang sama seperti menyikat gigi hanya 1 (satu) kali dalam sehari yaitu pada saat mandi saja dan lebih sering tidak menyikat gigi pada saat setelah makan, dan pada umumnya tidak mengetahui cara menjaga kebersihan gigi dan mulut.

Hasil uji independent $t$-test $\quad p=0,430>\alpha=$ $0,05, \mathrm{H}_{\mathrm{o}}$ diterima $\mathrm{H}_{\mathrm{I}}$ ditolak artinya tidak ada perbedaan status kebersihan gigi dan mulut antara SDN 1 Mundung dan SDN 2 Mundung. Kondisi ini di sebabkan karena faktor homogennya responden baik dari aspek tingkat usia ,tingkat kelas, serta aspek lingkungan sekolah terutama berkaitan dengan ketersediaan jajanan. Faktor penunjang dalam penelitian ini oleh kebiasaan dan kepatuhan responden. Seseorang dikatakan patuh bila menuruti apa yang telah ditentukan sesuai dengan jadwal yang telah ditetapkan serta melaksanakan apa yang telah dianjurkan juga seseorang dapat melakukan tindakan tersebut karena ada manfaatnya.

\section{KESIMPULAN}

Berdasarkan hasil penelitian yang dilakukan di SDN 1 dan SDN 2 Mundung Kecamatn Tombatu Timur menunjukkan bahwa rata-rata OHI-S SDN 1 Mundungyaitu 2,218 sedangkan rata-rata OHI-S SDN 2 Mundung yaitu 2,054, dengan nilai $\mathrm{p}=0,430>\alpha=0,05$. Hal ini kesimpulannya bahwa tidak ada perbedaan status kebersihan gigi dan mulut pada SDN 1 dan SDN 2 Mundung Kecamatan Tombatu Timur.

\section{SARAN}

Setelah melakukan penelitian dan membahas hasil penelitian ini maka penulis dapat memberikan saran yaitu :

1. Bagi siswa SDN 1 dan SDN 2 Mundung Kecamatan Tombatu Timur

a. Rajin menyikat gigi minimal 2 kali sehari yaitu pagi sesudah sarapan pagi dan malam sebelum tidur.

b. Mengurangi makan makanan yang manis dan lengket.

c. Rajin mengkonsumsi buah-buahan yang berserat dan berair.

d. Gigi yang sudah ada karang gigi dan gigi yang berlubang dilakukan pembersihan gigi dan penambalan gigi ke poli klinik gigi atau puskesmas agar gigi menjadi bersih dan sehat.

2. Bagi Pihak Sekolah agardapat mengadakan kerjasama dengan puskesmas untuk membuat program penyuluhan tentang kesehatan gigi dan mulut secara berkala dan berkelanjutan. Dan melakukan program usaha kesehatan gigi sekolah (UKGS) secara berkala 6 bulan sekali untuk meningkatkan kesehatan gigi dan mulut siswa.

3. Bagi peneliti selanjutnya agar dapat meneliti variable yang berbeda tentang perbedan status kebersihan gigi dan mulut.

\section{DAFTAR PUSTAKA}

1. Gopdianto, Randy., Rattu, A. J. M., \& Mariati, N.W. (2015). Status Kebersihan Mulut dan Perilaku Menyikat Gigi Anak SD Negeri 1 Malalayang Jurnal e-Gigi (eG) 3 (1:130138).Manado.

2. Kementrian Kesehatan, RI. (2013), Riset Kesehatan Dasar. Badan Penelitian dan Pengembangan Kesehatan RI. Jakarta. 
3. Sintawati \& N, Tjahja.(2008). Factor-Faktor Yang Mempengaruhi Kebersihan Gigi Dan Mulut Masyarakat DKI Jakarta.Jurnal Ekologi Kessehatan. 8 (1: 867).

4. Wirata, I. N., Agung, A. G. A., \& Nuratni, N. K. (2016). Perbedaan derajat kesehatan Gigi dan Mulut pada Siswa SD dengan program UKGS Akif dan tidak Aktif di Wilayah kerja Puskesmas Denpasar Utara II. Jurnal Ilmu dan Teknologi Kesehatan, 3 (2 : 124-136).diakses april 2016

5. Putri, M. H., Herijulianti, E., \& Nurjanah, N. (2010). Ilmu Pencegahan Penyakit Jaringan Keras dan Jaringan Pendukung Gigi. EGC. Jakarta. 